\title{
Tres Facetas de la Poesía Uruguaya Joven
}

\begin{abstract}
UIERO hablar aquí de tres autores muy poco conocidos, con la esperanza de que se preste la atención necesaria a la poesía uruguaya más reciente. He elegido tres nobles voces líricas, tres juventudes ardientemente democráticas y laboriosas: Ana Amalia Clulow, maestra normal; Selva Márquez, que presta su activa colaboración en tareas culturales de una radiodifusora uruguaya, y José Lucas, que cursa estudios de derecho. Los tres han realizado ya una bella labor, están llenos de fe, de vida, de entusiasmo, de dinamismo, y requieren la comprensión y el estímulo de sus hermanos de todo el Continente.
\end{abstract}

\section{ANA AMALTA CLULOW}

Ana Amalia Clulow pertenece a una familia de intelectuales y de artistas. Dos de sus hermanos son poetas: Carlos Alberto y Guillermo Eduardo. E1 primero de ellos es, además, un erudito y certero ensayista, que ha estudiado con autoridad la biología de la democracia. Guillermo Eduardo completa su vocación lírica con el arte del dibujo. Todos los libros de Ana Amalia están finamente ilustrados por el hermano artista últimamente citado.

Sangre escocesa corre por las venas de esta uruguaya, que diariamente comparte su cultivo de la poesía con la tarea -gratísima a su espíritu- de dictar sus clases en una escuela primaria de Montevideo. Felices los niños que aprenden la lección de labios de una hermana mayor tan comprensiva, tan noble. En sus propios versos, 
su amor a la escuela ha inspirado muchas de sus páginas más representativas.

Ana Amalia publicó su primer libro, Anfora de bronce, en 1930. Dos características especialísimas apuntaban ya en ese libro de adolescencia: una definida, rotunda tendencia al cultivo del verso libre (¿amor a la libertad, proveniente de su sangre británica?) y una total ausencia de énfasis. Sus motivos son de una muy loable sencillez, tomados de la vida diaria, a los que su genuino temperamento lírico comunica un soplo de belleza generosa.

El trompo de colotes

Gira, gira, poliedro multiforme,

carne de colores,

gira sobre la tierra,

que el hilo te arrancó la danza

loca de acrobacias;

gira, que el niño romperá su alegría

vibrante de colores;

gira, que esos ojos claros

están ansiosos por verte danzar.

Trompo

danzarin,

trapecista del hilo sutil,

baila, que al bailar

vibra tu carne de colores.

Cuando te canses, el niño te volverá

a enrollar

y romperás de nuevo su alegria

con tu eterno bailar.

Trompo:

gira, gira, gira,

poliedro multiforme,

trompo de colores;

gira, gira, gira,

que en la vida también gira el corazón.

Pertenece esta poesía a la segunda parte del libro, denominada "Rondas escolares", en la que Ana Amalia ha poetizado lindamente sus emociones e imágenes de la escuela, entre sus niños bienamados. Sin embargo, no todo ese libro tiene un carácter así, de fiesta y color. Hay en él también algunas destacables páginas de severo tono sub- 
jetivo, tales como: "Ceguera", "Invocación", "Veinte cantos", "Canto a la inmovilidad".

A los cinco años de publicado su primer libro, esta artista uruguaya acrecienta su bibliografía con la publicación de Caracol marino, obra que, al continuar la veta personal de Anfora de bronce, la ahonda con un notable progreso, sobre todo en lo que se refiere a los medios expresivos, que en el primer libro aparecerían, a veces, demasiado espontáneos. Así, en este segundo libro, tal espontaneidad aparece más depurada, más sintetizada y afinada. $Y$, sobre todo, Ia raíz británica de esta escritora tan uruguaya, se alarga en una floración marina. Ella trae el atavismo de su raza marinera, que le dice hermosos cantos con olor a salitre, con vastedad de horizontes líquidos :

\section{Marinerito inglés}

Marinerito rubio, de anchos pantalones

y albo blusón;

botines de cuero, de suelas claveteadas

y gorra azul.

Marinerito rubio de los lejanos mares del Norte,

que llegas al Plata por el ancho mar.

Tu barco está amarrado

a los muelles grises de mi ciudad

y tú paseas por ella con los ojos vivos

de curiosidad.

Alguien te ha dicho una frase amable

en tu idioma natal

y tú has dejado tu ancha sonrisa

llena aún de infantilidad.

Yo también te he sonreido y te he mirado

a los ojos, bravo marinerito inglés.

$Y$ has seguido con tu paso apresurado

por las calles Iuminosas de mi ciudad.

Me has traido en tus ojos un jirón de mi raza,

vieja amante del mar.

Marinerito rubio, de anchos pantalones

y albo blusón;

botines de cuero, de suelas claveteadas

y gorra azul.

Marinerito rubio de los lejanos mares del Norte, que llegas al Plata por el ancho mar.

Te llevarás de mi tierra un puñado de sonrisas, un montón de frases amables 
y otras... que no comprenderás jamás.

Entre los morenos muchachos de mi tierra,

fuiste tú, tan amigo de la niebla,

un manchón de sol.

Cuando partas, más allá del horizonte,

yo veré la bandera de Inglaterra

orgullosa, erguida, libre, valiente.

Levantaré mi mano curtida de sol,

$y$ te diré sonriente en la larga distancia:

"Good-bye".

Marinerito rubio de la libre Inglaterra,

que llegaste al Plata por el ancho mar.

La emoción de este poema aparece también finamente matizada en las páginas que se titulan "Caracol marino", "Cuéntame", "Canto marinero" y otras. Aunque el título general de este segundo libro es acertado, putes son los poemas de mar los más expresivos de la colección, corresponde destacar que en ella hay, dentro de su perfecta unidad, otros matices, tomados de la vida montevideana. En esta artista, su sangre británica no llega a ser una perenne nostalgia, sino que viene a dar como un nuevo impulso dinámico a su laboriosidad educativa y estética de uruguaya de la nueva generación.

Así, en su tercer libro, es sobre todo la maestra joven y comprensiva, rodeada de su pajarera de niños, la que poetiza sus impresiones, sus visiones, sus imágenes, su amor a la vida y a la naturaleza, a todo lo que es puro y es limpio y es bello y es sano y es bueno. Con finas ilustraciones de su hermano Guillermo Eduardo, Cajita de cristal es uno de los mejores libros de Ana. Allí, los juegos de los niños, la muchachita lituana que llega a clase, la capillita del pueblo, los gallos, la flauta, las margaritas, los cantos del pequeño coro, el ramo de violetas, los pájaros, la isla, el buque, el arcoiris, Pinocho, los perros. $Y$, sobre todo, el canto al niño triste que tiene la gran felicidad, el gran alivio de llegar a la escuela de una maestra buena $\mathrm{y}$ artista:

\section{Silencio}

Nueve años.

Jamás te he visto jugar, ni te he sentido cantar.

Eres como un pájaro entre manos ásperas. 


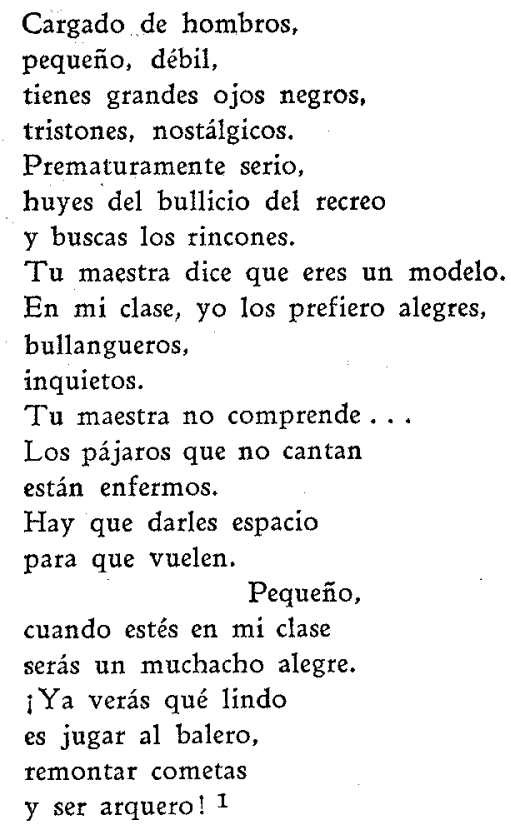

Al año siguiente de publicar esa lindísima Cajita de cristal, Ana Amalia -que junto al mérito intrínseco de su obra tiene el de su laboriosidad- publicó Las fogatas de San Juan, libro en prosa, libro de poesía. En él podemos valorar de una manera más amplia -en cuanto a la vibración humana- la personalidad de la autora, cuyos versos, de un valor estético superior a su prosa, no tienen, claro está, el sentido social de muchas de las más expresivas páginas de las citadas Fogatas de San Juan. El libro se divide en dos partes: "Historias de una colegiala" y "Relatos de una maestra". La primera reúne quince títulos correspondientes a prosas poemáticas que a veces son verdaderos cuentos, deliciosos de color y evocación. Se destacan especialmente "Tréboles", "Piratas", "Días de estudiante". Los "Relatos de una maestra", compuestos de catorce capítulos, son en realidad más ricos en conceptos que captan palpitaciones humanísimas, de calor social. Son, especialmente, sus experiencias de maestra de una escuela de niños pobres, su fe de poeta que, tanto como a la belleza, ama a la democracia. Estos nobilísimos conceptos estaban, es cierto, en algunos de sus versos. Mas la autora, guiada por un certero instinto lírico, no había acentuado el tono intelectual. $\mathrm{Ha}$ 
considerado - y estamos de acuerdo- que ese mensaje, en toda su vastedad, requería la prosa.

Ana Amalia tiene actualmente dos libros inéditos: uno titulado Moneditas de cobre; el otro, Montevideo. De este último separaremos una página muy expresiva, que marca un notable progreso en su carrera artística:

\section{Ciudad de Montevideo}

Ciudad de todos mis encuentros $\mathrm{y}$ de todas mis búsquedas ansiosas.

Me crié mirando el gris pizarra de los rostros de tus aceras.

$Y$ el nervioso guiño de las estrellas en las noches de luna llena.

En los dias de estudiante mi intranquilo andar pulsó los nervios de tus calles.

Ahora te estoy viviendo en este andar sin rumbo.

(Distraído rostro para el guiño de tus luces.)

Regreso costeando tu bahía. Los palos grises de los mástiles se me quiebran como cristales.

$Y$ pierdo en cada tarde

la transparencia de un sueño.

Cuando logro alcanzarlo, el gris pizarra de la ciudad pierde todos mis encuentros.

Ahora que te alzaste en altas torres están más azules que nunca el mar, el cielo. ${ }^{2}$ 
SELVA MARQUEZ

Escuchemos! Por favor, escuchemos!
Que cese el manubrio del piano rodante
que mastica las vértebras de la hora!
Que callen las bocas de los cromos
y de las botellas con olor a sueño!
Que calle el ruido inmenso de la bola
que empujan los escarabajos,
y el de la risa obscura de la taba,
y el cascado rodar
de los amores con taxímetro.
Alguien está llamando en algún lado!
Su voz rompe los vientos,
se asoma a las corolas y a los niños,
está en la lengua de los muertos!
Alguien está llamando en algún lado!
Ayudadme a escuchar, que yo no puedo! 3

Con esta poesía se abre el libro titulado El gallo que gira, que Selva Márquez publicó en 1941. Y es bastante representativa de la personalidad de la autora, especialmente en lo que se refiere a su hondura y a ciertos aspectos de su expresión, que se ensanchan y se coloran a medida que penetramos en ese libro, extraño, bello, muy original. Libro humano, humanísimo, pese a que su lenguaje - a veces algo hermético- parezca esconder tal sentido. En la poesía de Selva Márquez no hallamos ninguna concesión al gusto vulgar, ninguna música fácil o efectista, ningún preciosismo. Arduo y fino es su lirismo, sintético y profundo. A veces, desconcertante, magníficamente desconcertante. Densa poesía, que toma de la vida la inspiración y las imágenes que clarifica y estiliza en la virtud de su vibración estética. Para este lirismo, no hay aspecto vital que no sea capaz de ser ennoblecido por la magia de la creación poética. Por eso, aparte de representar un generoso esfuerzo digno de una auténtica individualidad artística, la poesía de Selva Márquez se destaca por su noble modernidad, que rehuye todo tema ya valorizado y busca hasta un nuevo lenguaje lírico, en el que no faltan a veces vocablos que aun ahora, por un exceso de tradicionalismo del sentido poético, parecían prosaicos. Pero que no lo son, cuando aparecen transfigurados por el sortilegio de la emoción y de la imaginación: 


\section{El niño pobre}

Cuando llora

riega una planta de cicuta.

Cuando llora

nace un escarabajo en la basura.

Cuando llora,

una serpiente

rompe la elipse hermética del huevo

y presta a Odio un nuevo diente.

Cuando llora,

los hombres están sordos y están ciegos!

Cuando llora,

sangra bajo la Cruz del Justiciero!

Ah! niño, niñito, niño,

que me avergüenzan tus ojos,

tus desnudos pies, tus manos,

promesa del trigo,

que me avergüenza ta frío

$y$ el recuerdo me lancea

por el otro niñito. Niño,

que tus lágrimas me siguen

calle abajo, calle artiba

y en una plaza me encuentran

$y$ en $m i$ propio espejo miran;

y escondo mi mano abierta,

cobarde mano ceñida

ahora, por el guante

de cabritilla.

Lloran: caminos de piedra!

Lloran: cruces! cruces! cruces!

Las palabras son abejas muertas cuando Iloran las nubes

$y$ cuando crecen cicutas $y$ ortigas

y florecen los árboles de ahorcados

y gime el niño de las espinas!

Cuando llora

es que nos hacen señas angustiadas

los muertos, con sus bocas! 4 
Esta página, a la vez que es una muestra del lenguaje poético de Selva Márquez, denota el sentido social de gran parte de su obra. Esa voz que se alza en defensa del niño pobre no necesita - para convencernos de la injusticia humana- de frases enfáticas ni de tono discursivo. Con su fino y recio lirismo, su mensaje llega al corazón. En otro bello poema, hallamos una emoción similar:

\title{
La puetta abietta
}

\author{
Pensamos una vez \\ que no había nada mejor que nuestra puerta \\ con su cerrojo bien echado \\ y su aldaba quieta. \\ La noche mordía como un ácido \\ el umbral y los clavos \\ y los pedidos de socorro se morían \\ de fatiga y de horrot a su costado.

\begin{abstract}
Alguna mano obscura nos llamaba arañando y golpeando...

La moneda de luz, en nuestra mesa, sobre la placidez de nuestras manos!

Fué cuando aquella calle se nos vino en oleadas de niños sin zapatos cuando en el hombro nos tocó la Mano!

Abrimos nuestras puertas a la noche y el dolor se hizo un hueco a nuestro lado!
\end{abstract}

Los tres intensos poemas que he transcrito pertenecen a $E l$ gallo que gira, el tercer libro que esta autora publicó (Montevideo, 1941). Su obra inicial, Viejo reloj de cuco, apareció en 1937. Le siguió el tomo titulado Dos, publicado en el mismo año. Si he elegido poemas de su más reciente tomo, al comenzar el presente estudio, es porque considero que ese libro es el que mejor y más ampliamente representa la personalidad de la autora. No quiero, sin embargo, desestimar sus dos obras anteriores. La primigenia reúne una serie de poemas que se caracterizan, sobre todo, por su fina emoción y por su gracia expresiva. Pero - salvo alguna excepciónno logran aquella fuerza sintética, aquella hondura de los poemas de 
El gallo que gira y de una parte de Dos. Sin embargo, ya en Viejo reloj de cuco aparecían presagios de la manera que más tarde -en un ritmo progresivo digno de todo elogio- definiría a la artista. A ese tomo inicial pertenecen estos fragmentos:

Si yo fuera la mano de Dios levantaba en seguida el sudario que ha cubierto las flores doradas: el sudario de asfalto ...5

... Tengo en mi mano el candelabro del día con sus veinticuatro luces pálidas y frías ... 6

... Bien sabemos qué cosas

hay al fin del camino

y qué brujas aguardan

y qué bandidos:

la duda, las cadenas

de siempre, los dolores

contra cuyas tizonas

nada pueden los hombres.

A'vancemos. De todos modos, siempre será lo mismo.

Todas las sendas, todas

llevan al gran camino. 7

Almas que fuimos árbol: hojas, sombras y trinos.

Nos hacharon las manos que labran los destinos,

nos ataron a un batco, sordas, ciegas y mudas...

E1 barco anda en las aguas más dulces o más rudas.

Nosotros no sabemos.

Parece que avanzamos...

iY es que avanzan los remos! 8

Las virtudes de intensidad y personalidad aparecen mejor expresadas en el segundo libro de Selva Márquez, titulado Dos. Este tomo tiene, aparte de muy bellas realizaciones líricas (tales como "La mujer que mató", "Viento norte", "Un niño llora", "La cabeza al revés", "Domingo de tarde"), la particularidad de presentar el único poema americano que conozco de esta autora. Es su título "Mulato", página honda, de rica imaginación y de expresión depura- 
da. A1 dar a este poema un significado tan especial, debo agregar que Selva Márquez es un espíritu universalista. De ninguna manera deseo reprochar en su lirismo la ausencia de elementos americanos. Ella cree en la mundialidad del espíritu humano. No la atraen los temas autóctonos. $\mathrm{Y}$ desde luego, creo que sería absurdo pedir -como hacen algunos críticos- que todos los artistas de nuestro Continente nos den en su obra un reflejo, ya objetivo o espiritual, de América, únicamente de América. Un americanismo integral necesita todos los elementos humanos y estéticos que forman, con amplitud y dignidad, la evolución de la cultura. En tal sentido es en el que destacamos, como una de las características más propias de Selva Márquez, su acento universalista. $Y$ corresponde también decir que en la ya referida página "Mulato", ella nos ha dado su único poema americano, su gran poema americano. Si bien su extensión no me permite reproducirlo integramente, transcribiré sus estrofas más intensas:

Intrincada y dura red su cabello de astrakán, donde ruedan cálidos reflejos de cobre.

Cándidas medias-lunas amanecen en la amatista de las uñas como en un crepúsculo morado.

Africa bate el tam-tam de vez en cuando sobre sus nervios y remece inconfesados sueños bárbaros con escenografías complicadas y totemes de barro.

Africa muerde sus talones y le moja los labios con la melaza negra de una música que unas veces es jazz y otras es tango.

Se le acerca el candombe con su pin-pa-ram-bum y sus llamas su perfume de axilas y sus carcajadas;

se le acerca en la caña 9 dormida en el vaso; 
se le acerca en la negra que pasa:

caderas por aquí, caderas por allá.

Mas de pronto, el orgullo del blanco

sacude su látigo

y el mulato vuelve de su sueño negro,

vuelve otra vez blanco, blanco, blanco!

Ay, mulato!

cual si en un cafetal

hubiera nacido de pronto una vara de nardo!

Que tengas tu orgullo, negro!

también tu orgullo! Yo sé,

mulato, lo que has de ser.

Porque tus dos razas juntas

forman el amanecer! 10

Creo que en ninguna poesía, ni aun en las de los propios poetas mulatos, empezando por el admirable Langston Hughes-, se ha expresado de manera tan intensa, imaginativa y original, la lucha de las dos razas. Y es tanto mayor el mérito del poema de Selva Márquez, por cuanto ella - mujer de blanquísima piel - no ha podido vivir esa tragedia. Pero el poeta tiene el don maravilloso del sueño - de gozar el sueño, de sufrir el sueño-y, gracias a tal don, esta uruguaya nos ha entregado un poema tan profundo. Hemos dicho $-\mathrm{y}$ con ejemplos abundantes- que el tercer libro de Selva Márquez, El gallo que gira -dividido en tres partes, lindamente denominadas "tres vueltas"-, es la obra que coloca a su autora en el grupo de las grandes poetisas actuales de América. Por la dignísima novedad de su visión estética, por su lenguaje arduo y fino, por su sentido humanísimo, El gallo que gira debe señalarse especialmente a la atención de la crítica. De sus versos puede decirse que, de acuerdo con Carlyle, "viven por la profundidad y la música de sus pensamientos". Ella nos da el poema desbrozado, depurado, en sus líneas esenciales. Frente a Selva, laboriosa, silenciosa, modesta - ¿ o quizá orgullosa, de una dignidad que rehuye, delicadamente, los elogios fáciles?-, un luminoso porvenir se abre magnánimo. $\mathrm{Y}$ con esto no queremos decir que se trate de una promesa. Sus obras -y, sobre todo, su tercer libro- ya han dicho ampliamente su verdad artística con nobleza y belleza que pueden, no obstante, ser superadas. 
JOSE LUCAS

Las tres presencias líricas de esta disertación están ordenadas, no sólo de acuerdo con su edảd, sino también siguiendo la cronología de su aparición en el ambiente literario. José Lucas publicó su primer libro en 1940. Este joven artista nació en Melo, capital del departamento de Cerro Largo. A esa ciudad - rodeada por la sonrisa estelar y átrea de los naranjales - corresponde el privilegio de ser la cuna de grandes poetas: Juana de Ibarbourou, Emilio Oribe, José Monegal, Lola Noblía de Plaza, Angelina Silveira Aguiar, etc. $\mathrm{Ha}$ sido, precisamente, Emilio Oribe, quien dió a José Lucas la bienvenida lírica con el siguiente soneto:

\title{
$A$ un joven poeta
}

\author{
Sueño que dioses buscas y presientes \\ un gran misterio en las celestes piras. \\ Sé que en las pampas hacia Dios suspiras \\ cuando la noche cae sobre las frentes. \\ Como tú fuí habitante de corrientes \\ que hoy sigues bajo cañas que son liras. \\ Sueño que estás allí y las aguas miras, \\ sueño que te hundes en mis viejas fuentes. \\ Joven: el río es Tiempo: en él van aves, \\ espejos, años, astros, mitos, claves. \\ ¿Tu canto quieres dar antes que asuma \\ la muerte los primores del estío? \\ Su ciencia de cristales te dé el río. \\ La poesía sus números de espuma.
}

Este denso y perfecto soneto figura al principio de la obra inicial de José Lucas, titulada El río de las cañas sonoras, traducción un tanto poética del nombre del río Tacuarí, que es precisamente el que en sus aguas refleja el cielo de Melo, la ciudad del poeta, la ciudad de poetas. ${ }^{11}$

Llama la atención, al recorrer las páginas de El río de las cañas sonoras, que se trate de una obra primigenia. Si bien es cierto que el autor no nos presenta ahí sus primeros "ensayos" (pues antes de 
editar su obra ya se había destacado por su colaboración en diversos periódicos nacionales), corresponde destacar que tanto en sus medios expresivos como en lo que se refiere a su visión poética, depuracla, El río de las cañas sonoras supera en mucho a lo que es, en la mayoría de los casos, el primer libro de versos de un joven.

Caracteriza la poesía de Lucas una noble valoración emotiva de todo lo que lo rodea. Su fina sensibilidad humaniza las cosas. Hay a lo largo de sus estrofas un tono místico que forma como un halo celeste. $\mathrm{Su}$ verso se ajusta a veces a las normas clásicas (especialmente en los romances); pero, en general, combina versos de ritmo tradicional, con otros libres, nuevos, formando una música sugestiva. Aun en los poemas de tono más nostálgico y evocativo, su emoción aparece sin excesos románticos, pues es poeta que sabe afinar su idioma lírico. He aquí, para demostrarlo, su "Elegía para la soledad de tu recuerdo":

Placidez infinita de la tarde que se alarga en los campos.

Hoy floreció en las sombras tu Recuerdo como un domido llanto.

Iba la noche desflorando estrellas con movimientos amplios.

(Así el destino separó de un golpe tu sombra de mi lado.)

Tu Recuerdo en la noche de mi vida tiene fulgor de astro.

¿Cómo urdiré las hondas resonancias que formarán su canto?

Para que Tú comprendas la dulzura que llevo entre las manos,

Para que sepas de las amarguras que anidan en mis labios,

Se ha prendido tu nombre en el silencio con un rumor de pájaro.

Pero la noche permanece muda al inútil llamado.

Los vientos de la Angustia hoy conmovieron las brumas del Pasado.

Y tu Recuerdo me besó como antes en los ojos cerrados . . . 12

Si bien este ambiente de ensueño y astralidad impera en el libro, no faltan en él algunas páginas que nos dan, en netos perfiles, una viva impresión de realidad. Así, "Las voces":

Era en la vieja iglesia blanquecina

de una ciudad lejana.

$Y$ era un coro de fuertes mocetones

de rostros suaves y robusta planta,

que en el silencio del recinto en sombras

cantaban...

A los acordes graves del armonio que en las humildes naves resbalaban, en una extraña conjunción melódica las varoniles voces se mezclaban. 


\footnotetext{
$Y$ me inundó de pronto la dulzura de aquellos labradores que cantaban, cuyos semblantes de morenos trazos la fe transfiguraba.

¿Qué mundo de encontradas sensaciones

el coro trasudaba!...

Pero de golpe se apagó en el eco

y yo torné de la emoción extraña.

... Las Voces! ...
}

Eta en la vieja iglesia blanquecina

de una ciudad lejana.

Los poemas titulados "Otoño en el cementerio" y "Plegaria para la virgen de un retablo familiar" son muestras cabales de cómo el poeta logra espiritualizar la realidad circundante, infundiéndole un soplo de mística sublimación. La pasión musical aparece noblemente expresada en los versos de "Danza de la vida breve", una de las páginas en que mejor pueden valorarse el instinto y la riqueza del ritmo de este poeta.

Tan hermoso libro, El río de las cañas sonoras, es hasta ahora el único que ha publicado José Lucas, de quien sabemos que prepara un segundo tomo, con notables progresos. Esos progresos ya se advierten en el delicado e intenso poema que, en un breve cuaderno de fina impresión, ilustrado por el propio poeta, apareció en 1942. Su título: "Alba-luna", cantata de los cuatro encuentros con la muerte. Su historia: la fraternal devoción del poeta por una exquisita criatura — “doblemente ángel"- llamada Lolita. Plaza Noblía, quien falleció en 1940, a los diecinueve años de edad. Era una destacada poetisa, hija de Lola Noblía de Plaza, autora de bellos y generosos poemas de orientación americanista y humanista. Al dedicar esta cantata a la memoria de su amiga ausente, José Lucas escribió cuatro de sus más bellos poemas. Lamentando que la extensión no me permita reproducirlos todos, escogeré un soneto de dicha serie, en que se advierte cómo la forma y la sustancia lírica del autor se han ido, cada vez más, afinando y condensando. Helo aquí:

Desdibujada flor de astronomía, Alba-luna, tu estela contra el río bajo herrambrosos álamos de estío desala al musgo su magnolia fría. 
Corza de nácar por la serranía sonámbula, tu fuga en extravío bruñe constelaciones al rocío, cuando apenas la noche es lejanía.

Alba-luna de muerte aquietadora, postrer candela fina de la aurora en obstinado viaje sin empeño.

¿Quién me diera morir, alucinado, con la fruta letal de tu costado tras la espigada soledad del sueño! ${ }^{13}$

Tal soneto, de expresión casi sobrerrealista -en su lenguaje de sueño y su música de imágenes-, debe ser considerado, sin duda, como una de las directrices que imperarán en la obra que el poeta dará en breve a la prensa.

Antes de escribir "Alba-1una", ya este uruguayo había dedicado al mismo tema un bello poema titulado "Pavana para una infanta muerta" (sobre un tema de Ravel). No resisto a la tentación de recordarlo, pues es de un lirismo muy puro:

Soledad de campanas en la noche llovidas sumergieron la adelfa de su frente partida. Quedó apenas el canto de una estrella en cenizas.

Herrumbrosos cipreses afiebrados de ausencia golpeteaban su nombre tras las búmedas piedras $y$ con llamas de llanto despertaban la tierra.

¿Dónde irá la infantina? - Al país de la lluvia. donde nadie reviste la carnal vestidura $y$ en juncales de hielo palidece la luna.

A ser llamada del viento, de la ola y la estrella, reposando en el musgo la esperanza secreta, que jamás viera abrirse su envoltura terrena.

Si el recuerdo traspasa los umbrales desiertos, como en cirio de leche los vitrales del sueño, Infantina, 
en el trance divino de andar,

' mi pañuelo

te despide en la noche del mar. .. ${ }^{14}$

Esta "Pavana" es una de las composiciones en que mejor puede apreciarse el instinto musical del poeta. Sin embargo, y pese a su nobleza lírica, debe destacarse que en recientes composiciones José Lucas ha logrado realizaciones de una más ajustada síntesis, sin perder nada de ese clima de vaga ensoñación, de mística bruma, que es uno de los valores más acentuados en la mayor parte de su obra. $\mathrm{Y}$ decimos en la mayor parte, por cuanto también cabe en su obra la nota social, siempre en una auténtica valoración de lirismo. Ya en El río de las cañas sonoras podía apreciarse, en los cuatro poemas de "Almería", cómo este poeta sabe enfocar el tema social con nitidez de poesía, es decir, sin perderse en el declive del prosaísmo o en el callejón del énfasis. Tales virtudes pueden admirarse más ampliamente en su más reciente poema, que es

Palabras en la Navidad de un soldado británico

Nunca sabré tu nombre,

ni la azulada huella de los mapas

donde quedó tu tiempo candoroso y anónimo.

En granjas escocesas, desceñidas de linos.

Junto a las torres con ladrillo y hiedra

de una iglesia de Gales.

Lejos, en Canadá o Australia,

o en las limpias ciudades que convergen

al africano Cabo de la Buena Esperanza.

Sólo sé

que eras dichosamente puro

antes del sueño negro de los dictadores.

$Y$ que esta Navidad ensangrentada,

Soldado del Imperio,

luchas pot mí y por todos los hombres de la Tierra

desde las alas rígidas de un pendón de Britania.

Minero,

partías las entrañas de la roca

por conseguir estrellas calientes de carbón.

Campesino, 
ibas tras los ganados rumorosos

- labrabas tu campo, pacífico y abierto.

Obrero,

el humo de las fábricas purificó tu esfuerzo.

Soldado,

hoy esculpe las tierras, los mares y los cielos

tu heroicidad que guarda las conquistas humanas.

Nunca sabré tu nombre...

Pero que Dios haga cercano el día

en que pueda gritarte con los brazos en alto:

¡Gracias, Soldado Inglés, que con tu sacrificio

me diste el día nuevo para alzar a mi Hijo! 15

\section{Gastón Figueira, Montevideo.}

\section{NOTAS}

1 Cajita de cristal, 58. El vocablo arquero, que aparece al final de esta poesía, se utiliza como sinónimo de guardavalla en algunos deportes, especialmente en fútbol.

2 Diario Uruguay, 14 de febrero de 1937. Montevideo.

3 El gallo que gira, 7.

4 Idem., 46 y 47.

5 Viejo reloj de cuco, 19.

6 Idem., 53.

7 Idem., 64.

8 Idem., 72.

9 El vocablo caña es muy utilizado en los países platenses para designar una bebida alcohólica muy popular, destilada de la caña de azúcar.

10 Dos, 12,13 y 14.

11 La tacuara es una especie de bambú que abunda en Uruguay, Brasil y otros países de América. Tacuatí, sería una contracción de tacuara-í ( $i$, en guaraní, significa agua, río). Por eso decimos que traducir Tacuarí por Río de las cañas sonoras es realizar un versión un tanto poética. Corresponde agregar que una de las variedades de la tacuara se denomina tacuarí.

12. El tío de las cañas sonotas, 35.

13 "Alba-1una", 2.

14 Diario Idea Nueva, Trinidad (Uruguay), 12 de junio de 1942, pág. 5.

15 Revista Mundo Utuguayo, Montevideo, 25 díciembre 1941, pág. 32. 